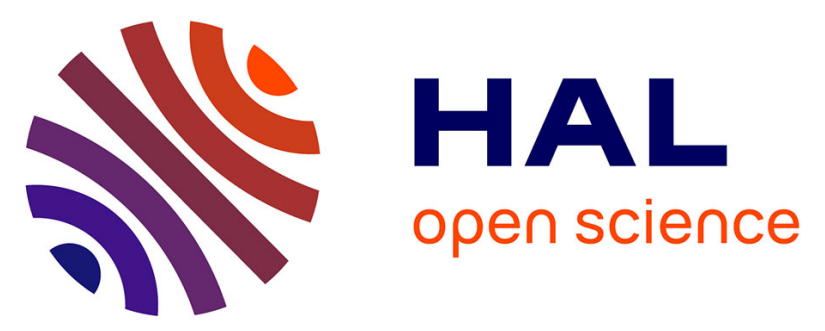

\title{
Enzymatic hydrolysis at high lignocellulosic content: Optimization of the mixing system geometry and of a fed-batch strategy to increase glucose concentration
}

Federico Battista, Mélanie Gomez Almendros, Romain Rousset, Pierre-Antoine Bouillon

\section{To cite this version:}

Federico Battista, Mélanie Gomez Almendros, Romain Rousset, Pierre-Antoine Bouillon. Enzymatic hydrolysis at high lignocellulosic content: Optimization of the mixing system geometry and of a fed-batch strategy to increase glucose concentration. Renewable Energy, 2019, 131, pp.152-158. 10.1016/j.renene.2018.07.038 . hal-02063461

\section{HAL Id: hal-02063461 \\ https://hal-ifp.archives-ouvertes.fr/hal-02063461}

Submitted on 11 Mar 2019

HAL is a multi-disciplinary open access archive for the deposit and dissemination of scientific research documents, whether they are published or not. The documents may come from teaching and research institutions in France or abroad, or from public or private research centers.
L'archive ouverte pluridisciplinaire HAL, est destinée au dépôt et à la diffusion de documents scientifiques de niveau recherche, publiés ou non, émanant des établissements d'enseignement et de recherche français ou étrangers, des laboratoires publics ou privés. 
ENZYMATIC HYDROLYSIS AT HIGH LIGNOCELLULOSIC CONTENT: OPTIMIZATION OF THE MIXING SYSTEM GEOMETRY AND OF A FED-BATCH STRATEGY TO INCREASE GLUCOSE CONCENTRATION

Federico Battista*, Mélanie Gomez Almendros, Romain Rousset, Pierre-Antoine Bouillon IFP Energies Nouvelles, Rond-point de l'échangeur de Solaize BP 3, 69360 Solaize, France *Corresponding Author: phone: +33437702143; email: federico.battista@gmail.com

\section{ABSTRACT}

Working at high values of lignocellulosic Dry Matter (DM), as wheat straw, increases the reaction medium viscosity, making the mixing inefficient with the traditional agitators. Batch and fed-batch tests were conducted using different impellers: i) inclined blades, ii) marine impeller, iii) anchor, iv) paravisc and v) double helical impeller. Inclined blades appeared an inadequate device for batch and fed-batch tests. On contrary, double helical impellers and anchor gave optimal performances. An alternative to improve the reactor's rheology is the modification of the feeding strategy. A particular fed-batch strategy allowed keeping low the reaction medium viscosity by a gradual increasing of the DM content in the reactor. In this way, three main benefits were achieved: i) a very good performances in terms of glucose concentration $(85 \mathrm{~g} / \mathrm{L})$, ii) a strong reduction of the energetic consumption compared to batch test and iii) the adoption of a simple mixing devise.

KEYWORDS: Bioethanol; High Dry Matter; Mixing; Enzymatic hydrolysis; Fed batch; Lignocellulosic materials 


\section{Introduction}

The conversion of lignocellulosic materials in glucose by enzymatic hydrolysis is a consolidate process in the biotechnological field [1] but requires improvements to be more economically advantageous, when the reactor works at high Dry Matter (DM) concentration. High DM content contributes to reduce the working volume, process water, capital costs and the energy demand for the following biological steps, i.e. the fermentation and distillation ones in bioethanol production [2], [3]. Previous studies on enzymatic hydrolysis of lignocellulosic materials at high DM content demonstrated that mass and heat transfer is inhibited in reactors operating with the most common impellers, i.e. Rushton or inclined blades [3], [4]. It depends on the recalcitrant nature of lignocellulosic polymers, which comports the increasing of the reaction medium's apparent viscosity. In particular Battista et al. [5] investigated on the correlation between the lignocellulosic physical characteristics and the viscosity within the reactor. They demonstrated that high porosity substrates, such as wheat straw (WS), have an elevated water adsorption tendency which, at high DM content, causes the increasing of reaction medium viscosity. Ghorbanian et al. [3] and Dasari and Berson [6] used no conventional reactor for the enzymatic hydrolysis at high DM concentration, adopting a Horizontal Rotating Reactor (HRR) rotating at very low speed to provide motion. They recorded a lower energetic power for the mixing than conventional stirred tank reactor and an adequate heat transfer. Despite these advantages, HRRs provided good mixing only in the angular direction of the motion, while in the case of enzymatic biomass processing, multidirection mixing and transport was needed to disperse enzymes and optimize sugars productions [7], [8]. As consequence, at the end of the enzymatic hydrolysis the sugars concentration was low [9], [10], [11]. In addition, HRR configuration was not adapted for big scales, such as industrial ones [12]. Thus, improving the rheology of stirred tank reactors represents the most convenient way to work at high DM lignocellulosic content.

The mixing performances of a stirred tank reactor are affected by several factors: the tank dimensions and its geometry (the Height/Diameter (H/D) ratio, the tank bottom morphology, the 
presence and number of baffles) [12]. The rotational speed of the impeller, which is strictly linked to the power supplied by the motor, is another important parameter to consider. Anyway, the impeller geometry (its shape and its dimensions) represents probably the most impacting factor on the mixing performance. Different geometries influence the intensities of the radial and axial boots changing deeply the reactor rheology. Anchor and helicoidal impellers, for example, are indicated for viscous reaction medium, while Rushton and inclined blades recorded very low performance in these conditions [12]. Finally, Mondebach and Nokes (2013) [13] also showed that the substrates feeding's strategy was a way to improve the rheology of the bioreactor. They demonstrated that fedbatch offers advantages in the enzymatic hydrolysis over the batch mode: the initial substrates quantity fed into the reactor was lower, so diffusion and mixing limitations can be minimized. In addition, fed-batch strategy permitted to the enzymes to better liquefy the recalcitrant lignocellulosic polymer.

The aim of this work was the investigation of the influence of the mixing systems geometry and of the reactor's feeding strategy on the enzymatic hydrolysis performances at high DM content. Impellers, having different diameter sizes and shapes, have been tested in batch and fed-batch mode. In addition, a fed batch strategy, the Fed Batch Gradual Addition (FBGA), has been implemented in order to simplify the reactor mixing devise and, at the same time, to have a high glucose concentration and a reduction of the energetic consumptions for the mixing.

\section{Materials and Methods}

\subsection{Characterization of the substrates and of the enzymatic cocktail}

Pretreated WS has been used for the tests. The pretreatment, conducted by an external company, consisted into the cutting of straws in $2 \mathrm{~mm}$ fibers, the soaking in an acid solution and the steam explosion process at $200{ }^{\circ} \mathrm{C}$ and 13.4 bar for 7.5 minutes. Pretreated WS had a DM concentration 
of $70.79 \% \mathrm{w} / \mathrm{w}$ and a cellulose content of $42.20 \pm 2.07 \% \mathrm{w} / \mathrm{w}$. Cellulose content in the pretreated WS has been determined by acid hydrolysis method [14].

Cellic CTec-2 (Novozymes) cellulase blend was used for all enzymatic hydrolysis tests. The enzymes concentration and the density of the enzymatic cocktail are $217.20 \mathrm{mg}$ protein $/ \mathrm{g}$ and 1.21 $\mathrm{kg} / \mathrm{L}$, respectively. The amount of the enzymatic cocktail was of $44 \mathrm{~mL}$ and has been determined through the methods by McIntosh et al. [15].

\subsection{The equipment}

The enzymatic hydrolysis of WS has been conducted in a 3L reactor (height $175 \mathrm{~mm}$, diameter base $150 \mathrm{~mm}$ ) (Figure 1), equipped with a torque meter Kistler 4503A measuring torque till a value of 2 $\mathrm{Nm}$ and with a data detection frequency variable from 1 to $10 \mathrm{~Hz}$. The reactor was also equipped with a water-heater and with temperature and $\mathrm{pH}$ control sensors.

In order to demonstrate the mixing system geometry's influence on the enzymatic hydrolysis at high DM conditions, five different impellers have been adopted for the tests (Figure 1). Two impellers were characterized by small diameter $(90 \mathrm{~mm})$ : the Inclined Blades Impeller (IBI) and the Marine Impeller (MAI). IBI was made in stainless steel and the blades was $20 \mathrm{~mm}$ high. An alternative version of IBI, the PLASTIC IBI, was realized in plastic by a 3D printer, and was adopted only for the group tests described in 2.3.2 paragraph. MAI was realized in plastic by a 3D printer too. Three different impellers with a big diameter $(140 \mathrm{~mm})$ have been also considered for the tests: the Anchor Impeller (AI), the Paravisc Impeller (PI) and the Double Helicoidal Impeller (DHI), all realized in stainless steel. The characterization of the impellers has been reported in Table 1. All the mixing systems have been located at $30 \mathrm{~mm}$ from the bottom of the reactor. 


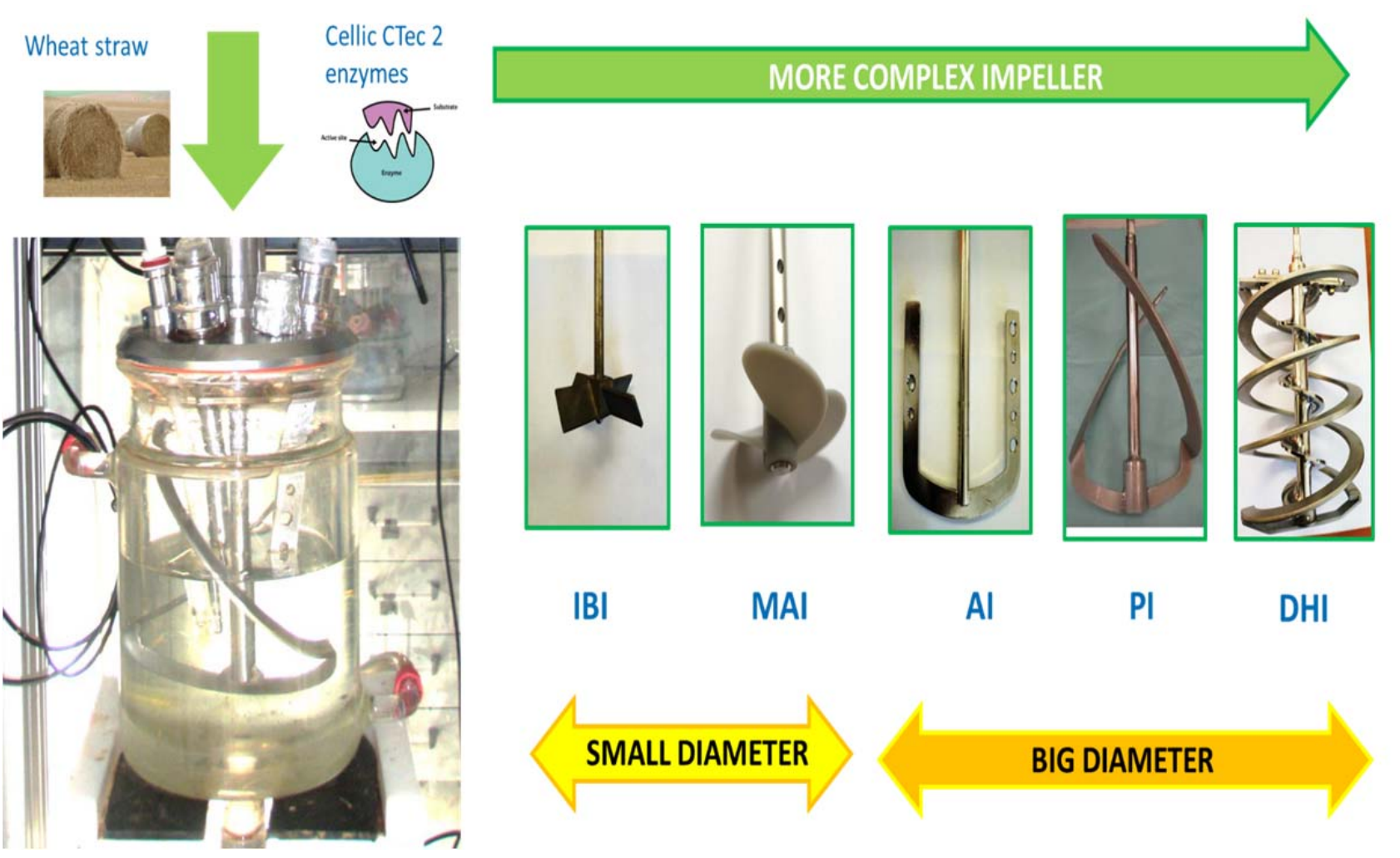

91 Figure 1. The reactor and the impellers used for the tests

92

\begin{tabular}{|lccc|}
\hline Impeller & Diameter $(\mathbf{m m})$ & Height of the blades $(\mathbf{m m})$ & Number of blades \\
\hline IBI & 90 & 20 & 4 \\
PLASTIC IBI & 90 & 40 & 4 \\
MAI & 90 & 20 & 3 \\
\hline AI & 140 & 100 & 2 \\
PI & 140 & 150 & 2 \\
& & & 2 \\
DHI & Internal helice: 50 & Internal helice: 155 & \\
& external helice: 140 & external helice: 160 & \\
\hline
\end{tabular}

Table 1. Characterization of the impellers used for the tests

\subsection{Description of the tests}

Two groups of tests have been conducted along this work. The first group consisted in Batch and

Fed-Batch 50 tests, with the aim to investigate the influence of the impeller geometry on the enzymatic hydrolysis. The second group has been realized to implement a fed-batch strategy, the FBGA, considering only the small diameter impellers: the MAI, the IBI and the PLASTIC IBI, 
which resulted inadequate in the previous Batch and Fed-Batch 50 tests. All tests have been

conducted in triplicate, to ensure their repeatability, at optimal operative conditions of $50^{\circ} \mathrm{C}, \mathrm{pH}$ in the range of $5.0-5.5 \mathrm{pH}$ was adjusted using a $\mathrm{NaOH}(2 \mathrm{~N})$ solution. The abbreviations and the descriptions of the tests have been reported in Table 2 .

\begin{tabular}{|c|c|}
\hline Labels & Description of the tests \\
\hline B-IBI & Batch test with inclined blades impeller \\
\hline B-MAI & Batch test with marine impeller \\
\hline B-AI & Batch test with anchor impeller \\
\hline B-PI & Batch test with paravisc impeller \\
\hline B-DHI & Batch test with double helicoidal impeller \\
\hline FB50-IBI & $\begin{array}{l}\text { Fed batch test with } 50 \% \text { of the total mass of the reaction medium loaded at the } \\
\text { beginning with inclined blades impeller }\end{array}$ \\
\hline FB50-MAI & $\begin{array}{l}\text { Fed batch test with } 50 \% \text { of the total mass of the reaction medium loaded at the } \\
\text { beginning with marine impeller }\end{array}$ \\
\hline FB50-AI & $\begin{array}{l}\text { Fed batch test with } 50 \% \text { of the total mass of the reaction medium loaded at the } \\
\text { beginning with anchor impeller }\end{array}$ \\
\hline FB50-PI & $\begin{array}{l}\text { Fed batch test with } 50 \% \text { of the total mass of the reaction medium loaded at the } \\
\text { beginning with paravisc impeller }\end{array}$ \\
\hline FB50-DHI & $\begin{array}{l}\text { Fed batch test with } 50 \% \text { of the total mass of the reaction medium loaded at the } \\
\text { beginning with double helicoidal impeller }\end{array}$ \\
\hline FBGA-IBI & Fed batch with gradual addition of WS. Metallic inclined blades as impeller \\
\hline FBGA-PLASTIC IBI & Fed batch with gradual addition of WS. Plastic inclined blades as impeller \\
\hline FBGA-MAI & Fed batch with gradual addition of WS with marine impeller \\
\hline
\end{tabular}

Table 2. Abbreviations and descriptions of the tests

\subsubsection{Batch and Fed-Batch 50 tests}

Batch and fed-batch 50 tests (Table 2) have been prepared in order to have a constant DM concentration of $20 \% \mathrm{w} / \mathrm{w}$, along all the test duration.

For batch tests the reactor was fed with $2.8 \mathrm{~kg}$ of WS-water mixture ( $0.85 \mathrm{~kg}$ of WS). These batch tests, where the entire reaction medium has been charged at the beginning of the enzymatic hydrolysis, represented the extreme situation for the mixing. In Fed batch 50 tests only the $50 \%$ of the $2.8 \mathrm{~kg}$ WS-water mixture was fed at the beginning of the tests. The rest of the mass has been added 10, 30, 60, 105 and 120 minutes after the beginning of the test in equal parts. At these times 
new WS addition. This criterion was not applicable for FB50-IBI which did not demonstrate improvements in mixing. The duration of each test has been established at 5 hours, while the mixing devices operated at $80 \mathrm{rpm}$.

\subsubsection{Fed Batch Gradual Addition (FBGA) tests}

FBGA tests (Table 2) have been conducted using only the small diameter size impellers (IBI, PLASTIC IBI and MAI). Compared to the previous fed batch strategy, where the DM concentration was always constant at $20 \% \mathrm{w} / \mathrm{w}$, the FBGA tests contemplated a gradual increasing of DM content during the test. 1,950 $\mathrm{g}$ of water and $250 \mathrm{~g}$ of WS have been charged in the reactor at the beginning of the test, then the remaining $600 \mathrm{~g}$ of WS have been fed after 1.0, 2.5, 3.5, 19.0 and 24.0 hours, to reach $20 \% \mathrm{DM} w / w$. In this way, a gradual liquefaction of the WS particles was possible, without overcoming the critical apparent viscosity, which has not allowed an adequate mixing with IBI and MAI in batch tests. The choice to adopt these small impellers does not constitute a contradiction. In fact, one of the major goal of this research is to demonstrate how feeding strategy can influence the reactor's rheology and allow the mixing system simplification. Therefore the positive performances of FBGA strategy with simple impellers are surely valid with the big diameter ones, which achieved good performance in batch test, where harder rheological conditions were applied.

To find the FBGA best operative conditions, three preliminary tests have conducted with IBI, which recorded the worst performances in the previous Batch and Fed-batch 50 tests:

a) To determine the FBGA ideal duration, a five days test has been realized, monitoring the energetic consumption to assure the mixing for gram of glucose produced. This test has been conducted at $80 \mathrm{rpm}$, in order to be compared with the previous ones

b) To verify the mechanical stress influence on the enzymatic activity, a test at high (200 rpm) rotational speed was conducted;

c) Tests with different enzymes strategy: i) Zero Enzymes test (ZE), where the $44 \mathrm{ml}$ of the enzymatic cocktail have been added at the beginning of the test, and ii) Gradual Enzymes 
(GE) test, where the $44 \mathrm{ml}$ of the enzymatic cocktail have been divided in 6 equal parts and added simultaneously with WS.

\subsection{Analytical methods}

The DM content of WS has been determined according to standard methods described in literature [16]. DM represents the content of solids present in the substrates, including the inert materials and the degradable ones [17].

The apparent viscosity of the WS-water mixtures have been determined at $20 \% \mathrm{DM} w / w$ before the beginning of the enzymatic hydrolysis. The equipment used for the apparent viscosity measurement and data recollection was the viscometer DV-II-PRO by Brookfield provided with a cross rotating spindle working at $80 \mathrm{rpm}$. The glucose concentration has been quantified by an enzymatic reaction using the GLUCOSTAT YSI2700. D-glucose determination was possible by the glucose-oxydase enzyme, immobilized in the Dextrose YSI membrane. The occurring reaction was the following:

Dextrose $+\mathrm{O}_{2} \rightarrow \mathrm{H}_{2} \mathrm{O}_{2}+\mathrm{D}-$ glucono- $\delta$-Lactone

The oxygen water produced by the previous reaction was oxidised by a silver electrode: the released electrical current was proportional to the glucose concentration.

\subsection{Definition of the parameters used for the evaluation of the tests}

The evaluation of the performances has been realised by three different parameters considering the most affecting factors all the bio-technological processes: the reaction medium fluid-dynamic, the mixing energy consumption and the glucose concentration.

\subsubsection{The Mixing Time}

Mixing time (tm) is the characteristic parameter used to investigate the performance of stirred tank reactors and it is often used as an indication of impeller effectiveness [18]. The shorter the mixing time the more effective the blending [19]. The mixing time was determined by the $\mathrm{pH}$ pulse method [20]: $10 \mathrm{~mL}$ of $\mathrm{NaOH}(2 \mathrm{~N})$ solution will be put in the reaction medium and the mixing time was estimated as the time required for the $\mathrm{pH}$ to reach $95 \%$ of its final value. The mixing time 
determination has been conducted at the beginning of the tests, when the adjustment of the acid reaction medium is necessary to reach the operative $\mathrm{pH}$ value of 5.5 , and at the end of the hydrolysis, before the discharging of the reactor.

\subsubsection{Power Input required by the mixing system}

The power consumption was determined from the torque meter values. Because of the friction factor, the torque generated by the motor $(\mathrm{Mm})$ is not fully transmitted by the impeller to the reaction medium [21]. The corrected torque value Mc was calculated by Equation 2:

$\mathrm{Mc}(\mathrm{Nm})=\mathrm{Mm}-\mathrm{Mr}$

where $\mathrm{Mm}$ is the measured torque and $\mathrm{Mr}$ is the residual torque, determined by measuring the torque at $50 \mathrm{rpm}$ in the empty vessel. The values of $\mathrm{Mm}$ were recorded each second by the torquemeter for all the duration of the test. An average value of Mc has been calculated by Excel each 15 minutes $(\Delta \mathrm{t})$ and used for the following calculation of the power $(\mathrm{P})$ and mixing energy consumptions (E):

$P(W)=M c 2 \pi N$

Where $\mathrm{N}$ is the rotational speed. Finally, the mixing energy consumption is given by the equation: $\mathrm{E}(\mathrm{J})=\Sigma \mathrm{P}_{\mathrm{i}} \Delta \mathrm{t}_{\mathrm{i}}$

Where $P_{i}$ is the power consumption for the th-esim time range $\Delta t_{i}$ of 15 minutes (900 s).

\subsubsection{Glucose concentration}

To evaluate the performance of the enzymatic activity, the cellulose conversion into glucose can be used [22]. The glucose concentration was measured at the end of each test.

\section{Results and Discussions}

\subsection{The influence of the impellers' geometry: Batch and Fed-Batch 50 tests}

Figure 2 summarizes the performances of the big diameter impellers during the batch test. The small devices IBI and MAI performances were not reported because the high reaction medium 
apparent viscosity (about $350 \mathrm{cP}$ ), which has not permitted an adequate mixing at 20\% $\mathrm{w} / \mathrm{w} \mathrm{DM}$.

MAI, in fact, assured the mixing only when the impeller rotational speed was increased to $250 \mathrm{rpm}$. than $10 \% \mathrm{w} / \mathrm{w}$.

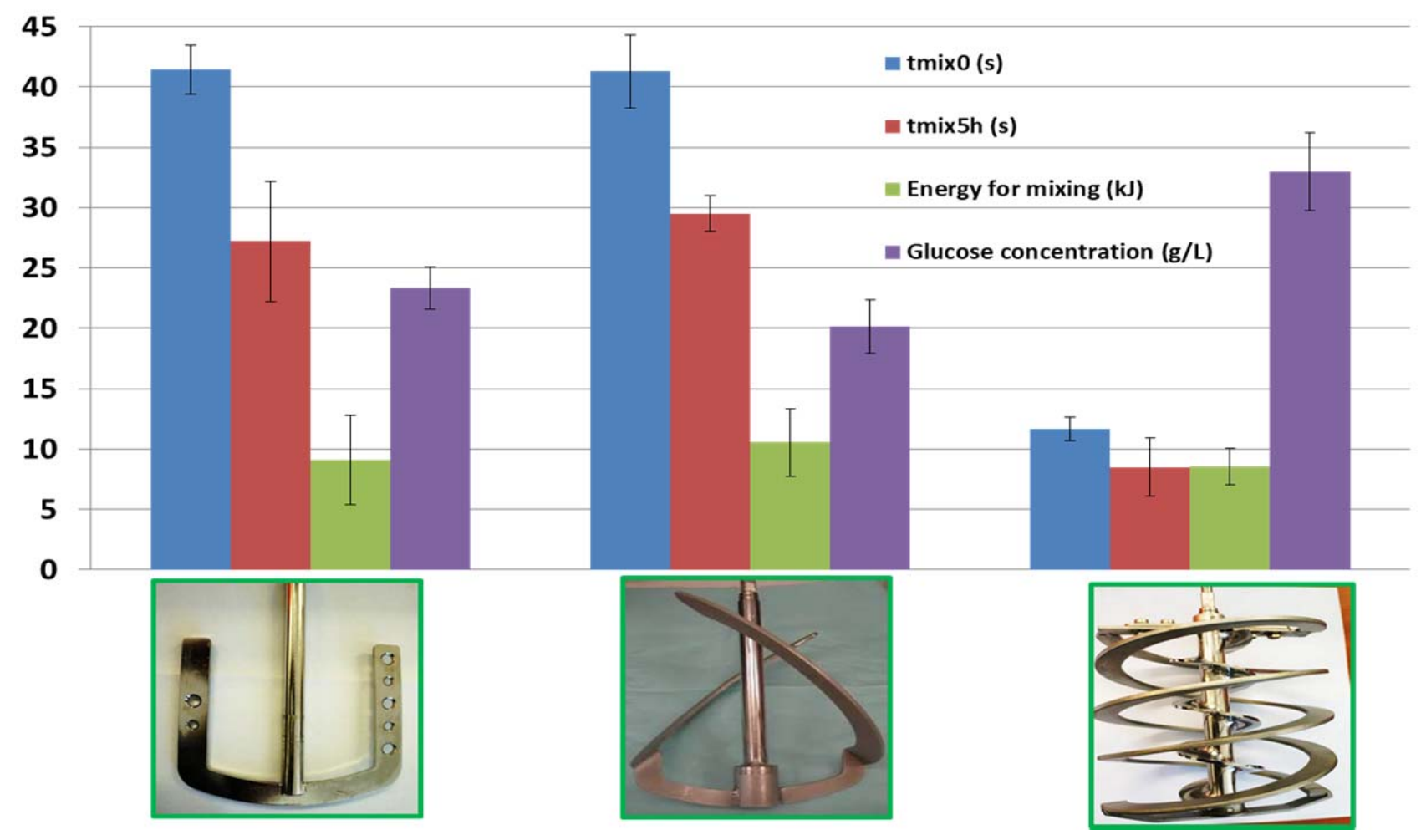

Figure 2. Mixing time, energy consumption for mixing and glucose concentration of the batch tests Instead, AI, PI and DHI, characterized by tall and big diameter blades, were able to supply a sufficient torque to guarantee the reaction medium mixing at $80 \mathrm{rpm}$. AI and PI achieved similar results (Figure 2): the mixing time at the end of the test were 27 and 29 s respectively, the energetic consumption for the mixing of 9.12 and $10.50 \mathrm{~kJ}$ and the glucose concentration of $23.36 \mathrm{~g} / \mathrm{L}$ and $20.12 \mathrm{~g} / \mathrm{L}$. Anyway, the mixing was not perfect with AI: a $15 \mathrm{~mm}$ layer of sedimented particles was present at the bottom of the reactor. Nagata [24] reported that AI is suitable for the mixing of viscous liquids, but is not recommended for completely uniform mixing. More recently, this concept has been confirmed by Patel et al. [25], who explained that AI primarily generates a strong radial boost, but is not able to assure an axial movement, indispensable to avoid particles 
sedimentation. For these reasons, a combination of AI with another impeller is recommended, to guarantee also some axial boots to the fluid [26].

The best performances with the batch mode have been achieved by DHI, the most complex impeller used along this work (Table 1). The DHI dimension and shape allowed assuring adequate radial and axial boots to all the mass of the reaction medium. The good mixing performances where certified by smaller levels of mixing time and energetic consumption of $8.5 \mathrm{~s}$ and $8.54 \mathrm{~kJ}$, respectively. The rheological improvements allowed the glucose concentration increasing to $33 \mathrm{~g} / \mathrm{L}$, confirming that the correlation between bioconversion activity and mixing [27].

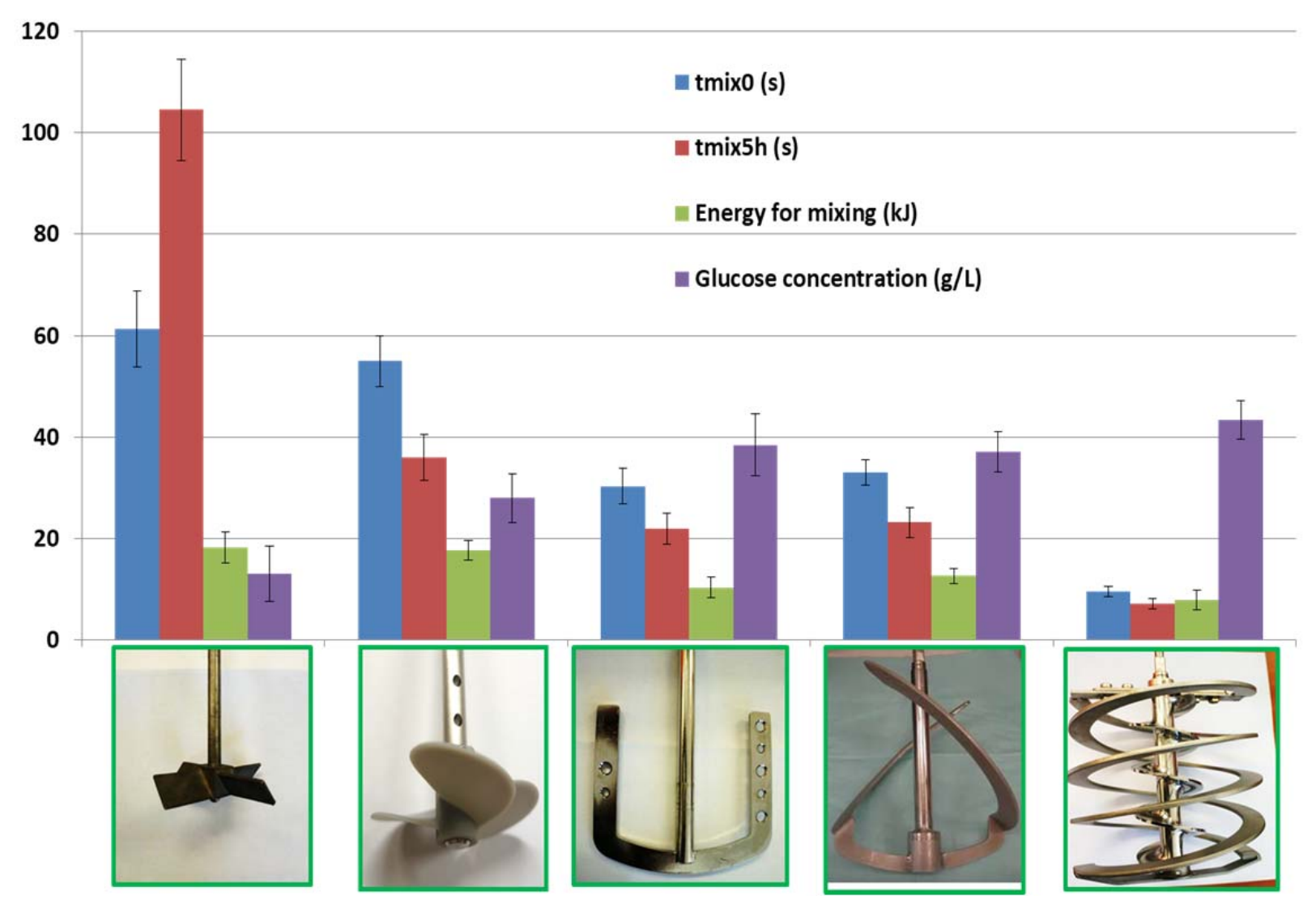

Figure 3. Mixing time, energy consumption for mixing and glucose concentration of the fed-batch 50 tests

Figure 3 shows the performances of the fed-batch 50 tests. The first relevant fact is that all the impellers were able to assure the mixing at $80 \mathrm{rpm}$. It depended to the feeding strategy: only the $50 \%$ of the total reaction medium was fed at the beginning of the test. In this way, the liquefaction of the particle of this first WS addition reduced the apparent viscosity from about $350 \mathrm{cP}$ to $80 \mathrm{cP}$, 
permitting the following WS additions. Fed-batch strategy, in fact, offers advantages in the enzymatic hydrolysis over the batch mode: the initial substrates quantity fed into the reactor is lower, so diffusion and mixing limitations can be minimized [13]. Anyway, the different impellers have not worked at the same way. The worst performances were obtained with the IBI, which was the unique case where mixing time increased during the enzymatic hydrolysis: it passed from 61 to $104 \mathrm{~s}$. The high value of mixing time at the beginning of FB50-IBI demonstrated that the mixing was not good. In addition, the liquefaction of the first $50 \%$ of the total WS mixture was not complete when the following additions occurred, giving a further increasing of the reaction medium apparent viscosity. Consequentially, the energetic consumption was the highest of all the fed-batch tests $(18 \mathrm{~kJ})$, while the glucose concentration the lowest $(13 \mathrm{~g} / \mathrm{L})$. B-IBI and FB50-IBI tests demonstrated that IBI was inadequate for the mixing of Non-Newtonian and viscous fluids, because it transmitted radial and axial boosts of weak intensity to the reaction medium, which can involve only the region close to the impeller blades, leaving stagnant conditions in the other regions of the reactor [25].

MAI achieved better performances: the mixing time decreased during the FB50-MAI test from $55 \mathrm{~s}$ to $36 \mathrm{~s}$, and glucose concentration reached the $28 \mathrm{~g} / \mathrm{L}$. This improvement is explicable considering the MAI shape, designed to transmit a strong axial boots [28], which assured the mixing at the whole reaction volume [17]. Anyway, the energetic consumption remained high of $17 \mathrm{~kJ}$, confirming that MAI was not the ideal configuration for high viscous fluid mixing. The performances of fed-batch 50 tests achieved by big diameter size impellers (AI, PI and DHI) have followed the same trends of batch tests (Figure 3). AI and PI obtained similar results, with marginal sedimentation phenomena with AI. DHI confirmed the best performances, with very low mixing time and energetic consumptions of $7.2 \mathrm{~s}$ and almost $8 \mathrm{~kJ}$ and a very high glucose concentration value of $43.4 \mathrm{~g} / \mathrm{L}$ after only $5 \mathrm{~h}$ of enzymatic hydrolysis. Feb-batch 50 's better performances can be also justified considering that the reaction medium gradual addition allow to minimize the enzymes deactivation phenomena. Some works, in fact, claim for inhibition of 
endoglucanases and exoglucanases when large concentrations of cellobiose and glusose, are present in the reaction medium. Cellobiose can be consider an intermediate product in enzymatic reactions which permit the cellulose degradation in glucose. Cellobiose is able to more affect exoglucanases and endoglucanases, whilst the action of $\beta$-glucosidases could be more affected by glucose when its concentration is more than $40 \mathrm{~g} / \mathrm{L}$ [29], [30].

\subsection{FBGA tests}

The rheology of the reactor are not dependent univocally by the geometry of the mixing device, but also by the strategy of the substrates addition, as remarked by Mondebach and Nokes (2013) [13]. In order to demonstrate the feeding strategy importance, the FBGA has implemented using simpler and smaller impellers.

\subsubsection{Operative conditions to optimize FBGA strategy}

As previously reported, three preliminary tests have been conducted to find the operative conditions which permitted to optimize FBGA strategy. Figure 4 shows the glucose concentration in the reaction medium and the amount of glucose produced for $\mathrm{kJ}$ of electricity used to assure the mixing. The glucose had an exponential increasing in the first 24 hours of the test, then the growth was slowest. 50-70 g glucose were produced for kJ during the first two hours of the test. The production was $10-15 \mathrm{~g} / \mathrm{kJ}$ after $24 \mathrm{~h}$, and it declined under $10 \mathrm{~g} / \mathrm{kJ}$ after $48 \mathrm{~h}$ from the beginning of the test. 


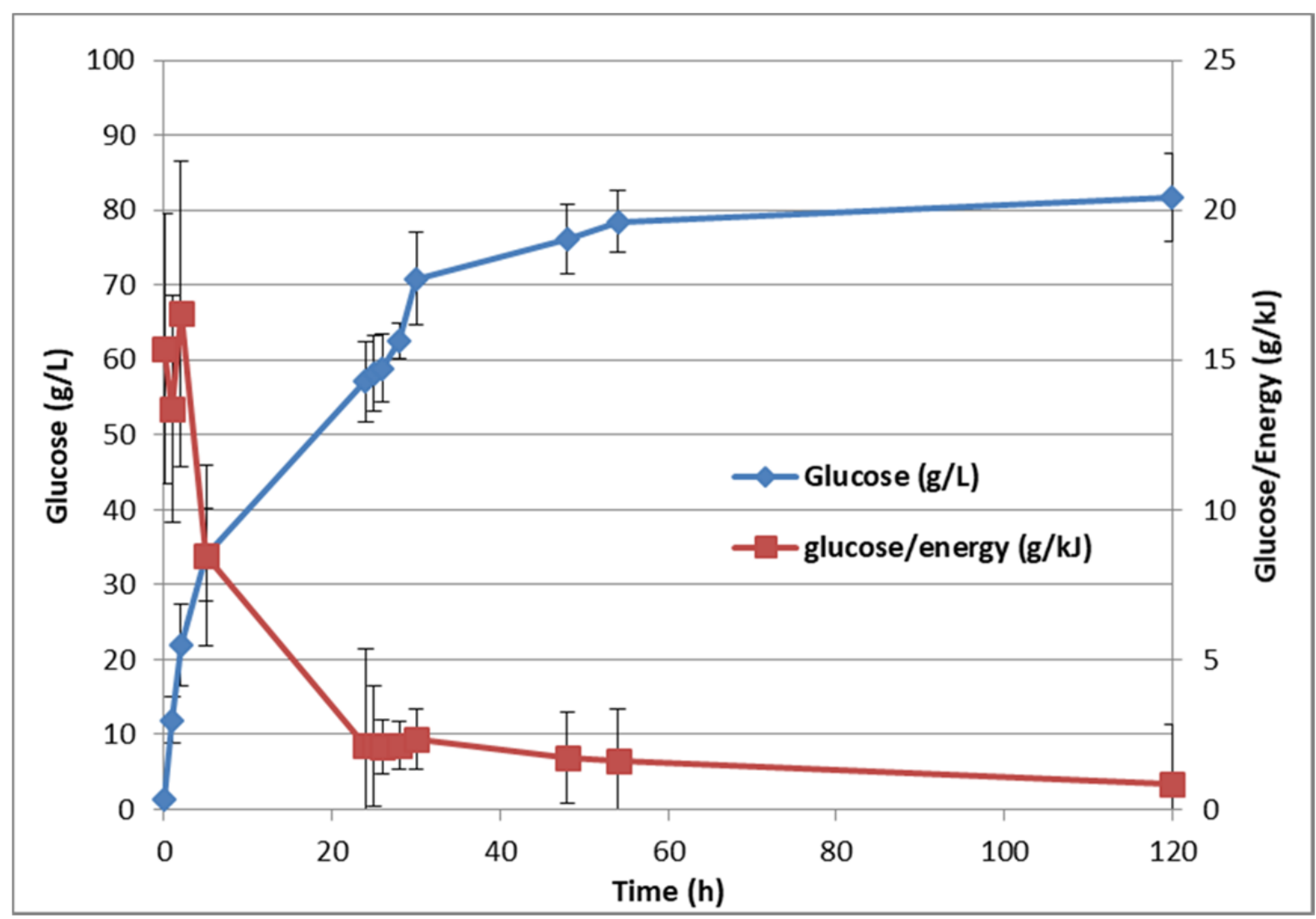

Figure 4. Trends of glucose and of glucose/energy ratio during enzymatic hydrolysis

For these reasons, the ideal duration for FBGA strategy has been stablished at $48 \mathrm{~h}$.

The impeller rotational speed was another important operative condition. The influence of low ( 80 rpm) and high (200 rpm) speed on the enzymatic hydrolysis was investigated (Figure 5). On one hand a slighltly improvement of the mixing time, from $12 \mathrm{~s}$ to $9.5 \mathrm{~s}$, has been found at $200 \mathrm{rpm}$. On the other hand, this not sensible reduction, was payed by a strong energetic increasing in the energetic consumption for mixing, whose value passed from $35 \mathrm{~kJ}$ at $80 \mathrm{rpm}$ to $56.5 \mathrm{~kJ}$. Lastly, working at high rotational speed reduced the glucose concentation of about $25 \%$, from almost 85 $\mathrm{g} / \mathrm{L}$ to $62 \mathrm{~g} / \mathrm{L}$. This phenomena is explicable considering the enzymes chemical nature. They are protein whose structure is stabilized by weak forces, where the free energy difference between the protein, whit concomitant reduction in activity [12]. In this case, mechanical stress, due to the high native and completely denatured state is often of few $\mathrm{kcal} / \mathrm{mol}$. Thus, a multitude of physical and chemical parameters can cause of perturbations of the geometrical and chemical structure of the rotational speed of the impeller, was the factor reducing the enzymatic activity and consequentially 
the glucose concentration of the test. The mechanical stress' removal usually comports a new increasing of the enzymatic catalysis but at lower levels than the original ones [31].

281 It was so demonstrated that FBGA was able to reach better performances in term of glucose 282 concentration and energetic consumption at low rotational speed and $80 \mathrm{rpm}$ was selected as 283 operative speed for FBGA strategy.

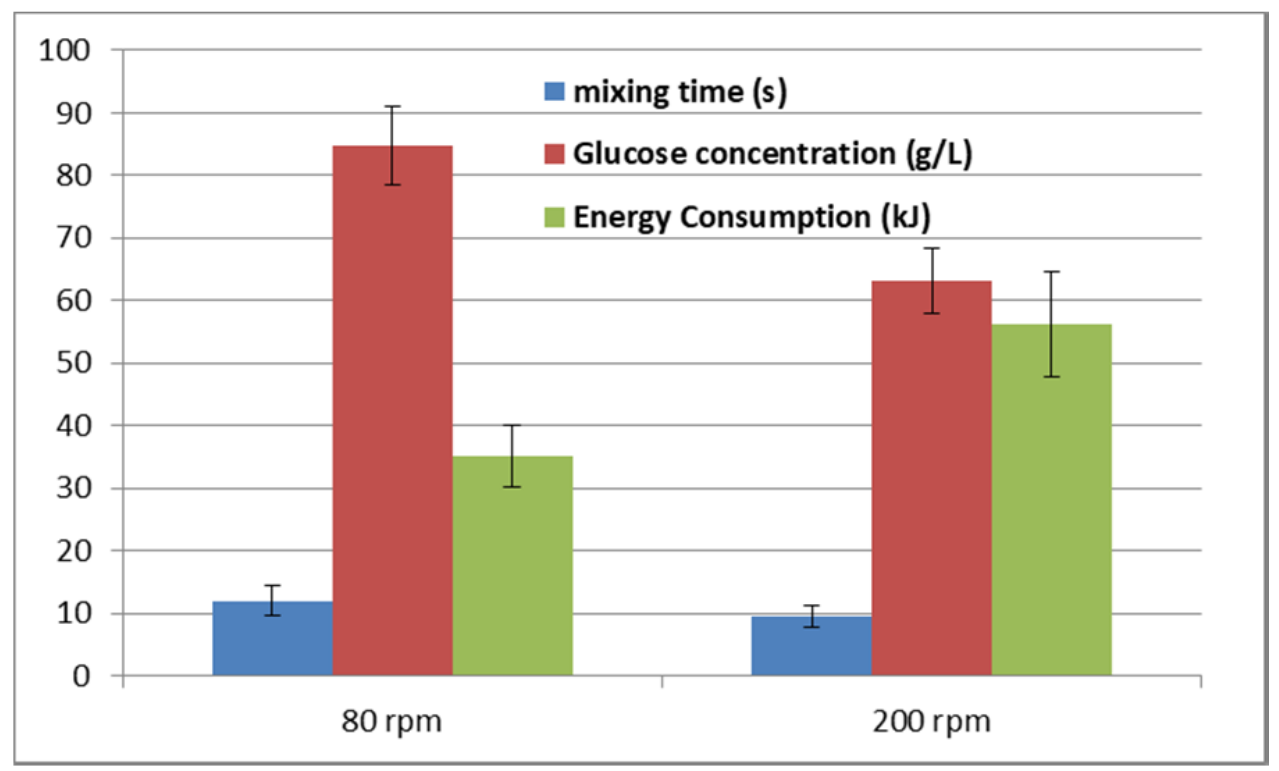

Figure 5. Effect of the rotational speeds on the enzymatic hydrolysis

Finally, the adoption of the best enzymes addition strategy has been investigated. Figure 6 shows the difference in glucose concentration between ZE and GE strategies.

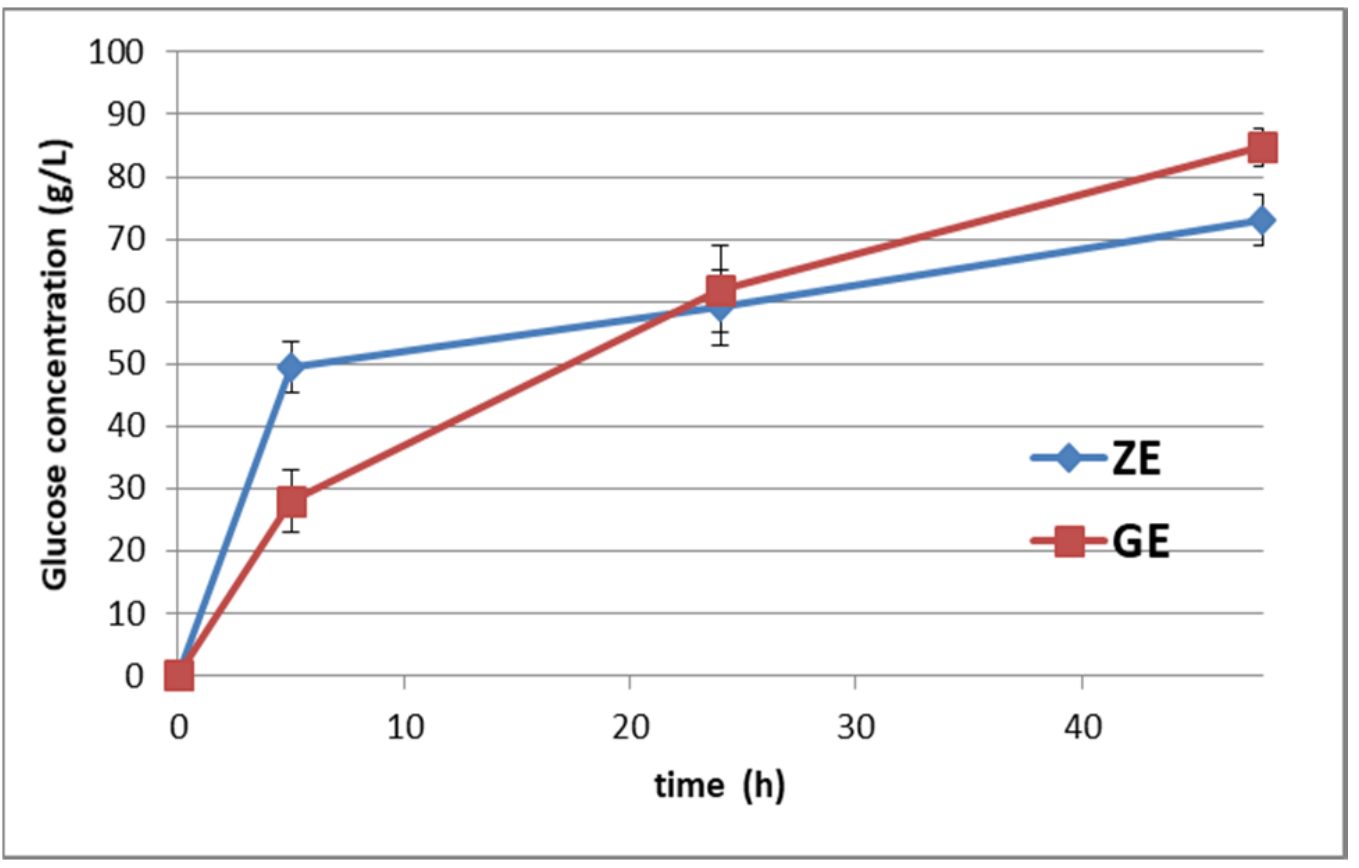


Figure 6. Effect of the enzymes addition strategy on enzymatic hydrolysis

The glucose growth was fast in ZE, where all the amount of enzymes was immediately available for the cellulose conversion. By the time, these too rapid glucose accumulation in the reaction medium, caused the inhibition of the enzymes. As previously described, it was demonstrated that cellobiose accumulation negatively affected exoglucanases and endoglucanases enzymes, while the $\beta$ glucosidases enzymes were more affected by a high glucose concentration [32]. Instead, the gradual addition of the enzymes in GE test permitted to replace the inhibited ones. The glucose increasing was slowest than ZE along the first $24 \mathrm{~h}$ of the test, but a higher glucose concentration was achieved at the end of the test (Figure 6). GE strategy was adopted for the FBGA tests.

\subsubsection{FBGA tests with small diameter impellers}

The optimized FBGA gave very good performances: MAI, IBI and PLASTIC IBI achieved a glucose concentration of $80-85 \mathrm{~g} / \mathrm{L}$, with a low energetic consumption between $35-40 \mathrm{~kJ}$ in $48 \mathrm{~h}$ of enzymatic hydrolysis. Three considerable goals were achieved by FBGA strategy: i) the improving of the cellulose conversion into glucose, ii) the simplification of the mixing system and iii) the reduction of the energetic consumption. These results demonstrate that viscosity problem is not present with FBGA strategy because it allows keeping the viscosity values always under the critical value beyond which the mixing was not efficient with small diameter impeller in batch and fedbatch tests, allowing the use of simple mixing devices.

\section{Conclusions}

The influences of the impellers geometry and of the feeding strategy on the enzymatic hydrolysis at high DM lignocellulosic content were studied. It was demonstrated that small and simple diameter were inefficacy in batch condition, while big diameter and complex impellers, especially DHI, had good performances in batch and fed-batch 50 modes.

Instead, FBGA strategy, optimized opportunely for high DM content, achieved the adoption of simple and small diameter, a very high glucose concentration and low energetic consumption for 
the mixing by a gradual DM increasing within the reactor. This allows to demonstrate that the rheology is influenced both by the impeller's geometry and by the reactor' feeding strategy.

\section{References}

[1] N. Tippkötter, A. A. Duwe, S. Wiesen, T. Sieker, R. Ulber, Enzymatic hydrolysis of beech wood lignocellulose at high solid contents and its utilization as substrate for the production of biobutanol and dicarboxylic acids, Bioresource Technology 167 (2014) 447-455.

[2] B. Palmqvist, M. Wiman, G. Liden, Effect of mixing on enzymatic hydrolysis of steampretreated spruce: a quantitative analysis of conversion and power consumption, Biotechnology for Biofuels 4 (2011) 10.

[3] M. Ghorbanian, D.C. Russ, R.E. Berson, Mixing analysis of PCS slurries in a horizontal scraped surface bioreactor, Bioprocess Biosyst Eng 37 (2014) 2113-2119.

[4] S. Rezania, Z. Ye, R.E. Berson, Enzymatic saccharification and viscosity of sawdust slurries following ultrasonic particle size reduction. Appl Biochem Biotechnol 153 (2009) 103-115.

[5] F. Battista, M. Gomez Almendros, R. Rousset, S. Boivineau, P.A. Bouillon, Enzymatic hydrolysis at high dry matter content: the influence of the substrates' physical properties and of loading strategies on mixing and energetic consumption, Bioresource Technology 250 (2018) 191-196.

[6] R. Dasari, R.E. Berson, The effect of particle size on hydrolysis reaction rates and rheological properties in cellulosic slurries, Appl Biochem Biotechnol 137-140 (2007) 289299.

[7] R.G. Sherritt, J. Chaouki, A.K. Mehrotra, L.A. Behie, Axial dispersion in the threedimensional mixing of particles in a rotating drum reactor, Chem Eng Sci 58 (2003) 401-415. [8] M. Hehl, H. Kroger, H. Helmrich, K. Schugerl, Longitudinal mixing in horizontal rotary drum reactors, Powder Technol 20 (1978) 29-37.

[9] Y.S. Lin, W.C. Lee, Simultaneous saccharification and fermentation of alkaline pretreated cogon grass for bioethanol production, BioResources 6 (2011) 2744-2756. 
[10] Y.S. Lin, W.C. Lee, K.J. Duan, Y.H. Lin, Ethanol production by simultaneous

saccharification and fermentation in rotary drum reactor using thermos tolerant Kluyveromyces marxianus, Appl Energy 105 (2013) 389-394. [11] A. Isci, J.N. Himmelsbach, J. Strohl, A.L. Pometto, D.R. Raman, R.P. Ane, Pilot-scale fermentation of aqueous-ammonia-soaked switch grass. Appl Biochem Biotechnol 157 (2009) $453-462$.

[12] J. Bailey, D. Ollis, Biochemical engineering fundamentals: second edition, McGraw-Hill,

[13] A.A. Mondebach, S.E. Nokel, Enzymatic hydrolysis of biomass at high-solids loadings - A Review, Biomass and Bioenergy 56 (2013) 526-544.

[14] A. Thygesen, J. Oddershede, H. Lilholt, A.B. Thomsen, K. Ståhl, On the determination of crystallinity and cellulose content in plant fibres, Cellulose 12 (2005) 563-573.

[15] S. McIntosh, Z. Zhang, J. Palmer, H. Wong, W.O.S. Doherty, T. Vancov, Pilot-scale cellulosic ethanol production using eucalyptus biomass pre-treated by dilute acid and steam explosion, Biofules, bioproducts and biorefining 10 (4) (2016) 346-358.

[16] APHA/AWWA/WEF, Standards Methods for the Examination of Water and Wastewater, United Book Press Inc.. Baltimore Maryland, 1998.

[17] F. Battista, D. Fino, G. Mancini, B. Ruggeri, Mixing in digesters used to treat high viscosity substrates: The case of olive oil production wastes, Journal of Environmental Chemical Engineering 4 (2016) 915-923.

[18] M. Jafari, J.S. Soltan Mohammadzadeh, Mixing time, homogenization energy and residence time distribution in a gas-induced contactor, Chemical Engineering Research and Design. 83 (A5) (2005) 452-459.

[19] M. Gumienna, M. Lasik, K. Szambelan, Z. Czarneck, Reduction of water consumption in bioethanol production from triticale by recycling the stillage liquid phase, Acta Sci. Pol. Technol. Aliment. 10 (4) (2011) 467-474. 
[20] D.F. Ryan, L.P.B.M. Janssen, L.L. van Dierendonck, Circulation time prediction in the scale-up of polymerization reactors with helical ribbon agitators, Chemical Engineering Science 43 (8) (1988) 1961-1988.

[21] X. Wang, L. Fradette, K. Takenaka, P. Tanguy, Effect of Operating Parameters on the Mixing Performance of the Superblend Coaxial Mixer, Industrial \& Engineering Chemistry Research 51 (2012) 1826-1833.

[22] L.J. Correa, A. Colli Badino, A. Cruz, Power consumption evaluation of different fed-batch 825-833.

[23] J. Du, Y. Li, H. Zhang, H. Zheng, H. Huang, Factors to decrease the cellulose conversion of enzymatic hydrolysis of lignocellulose at high solid concentrations, Cellulose 21 (2014) 2409-2417.

[24] S. Nagata, Mixing: Principles and Applications, Kodansha, Tokyo, 1975.

[25] D. Patel, F.E. Mozaffari, M. Mehrvar, Improving the dynamic performance of continuousflow mixing of pseudoplastic fluids possessing yield stress using Maxblend impeller, Chem. Eng. Res. Des. 90 (2012) 514-523.

[26] R.P. Chabra, J.F. Richardson, Non-Newtonian Flow and Applied Rheology, Engineering Application, 2nd ed., Elsevier, Butterworth-Heinemann, Amsterdam, 2008.

[27] U. Mais, A.R. Esteghlalian, J.N. Saddler, Influence of mixing regime on enzymatic saccharification of steam-exploded softwood chips, Appl Biochem Biotechnol 98 (2002) 463472.

[28] K.J. Lee, T. Hoshino, J.H. Lee, A lifting surface optimization method for the design of marine propeller blades, Ocean Eng. 88 (2014) 472-479.

[29] Y. Xue, H. Jameel, S. Park, Strategies to recycle enzymes and their impact on enzymatic hydrolysis for bioethanol production, Bioresources, 7 (1) (2012) 602-615. 

lectures, American Chemical Society, Washington, 1983.

394 [31] S.I. Mhlongo, R. Haan, M. Viljoen-Bloom, W.H. van Zyl, Lignocellulosic hydrolysate 395 inhibitors selectively inhibit/deactivatecellulase performance, Enzyme and Microbial $396 \quad$ Technology, 81 (2015) 16-22. [32] A. Arora, E.M. Martin, M.H. Pelki, D.J. Carrier, Effect of formic acid and furfural on the enzymatic hydrolysis of cellulose powder and dilute acid-pretreated poplar hydrolysates, Acs Sustain. Chem. Eng. 1 (1) (2013) 23-28.

400 
LIST OF CAPTIONS

402

Figures

403 Figure 1. The reactor and the impellers used for the tests

404 Figure 2. Mixing time, energy consumption for mixing and glucose conentration of the batch tests

405 Figure 3. Mixing time, energy consumption for mixing and glucose concentration of the fed-batch $406 \quad 50$ tests

407 Figure 4. Trends of glucose and of glucose/energy ratio during enzymatic hydrolysis

408 Figure 5. Effect of the rotational speeds on the enzymatic hydrolysis

409 Figure 6. Effect of the enzymes addition strategy on enzymatic hydrolysis

410 Tables

411 Table 1. Characterization of the impellers used for the tests

412 Table 2. Abbreviations and descriptions of the tests 